\title{
Morphodynamic Modelling with Uncertain Geometry Input
}

\author{
Jakob Siedersleben *, Stefan Jocham, Markus Aufleger (D) and Robert Klar (D) \\ Unit of Hydraulic Engineering, Faculty of Engineering Science, University of Innsbruck, Technikerstraße 13, \\ 6020 Innsbruck, Austria; stefan.jocham@uibk.ac.at (S.J.); markus.aufleger@uibk.ac.at (M.A.); \\ robert.klar@uibk.ac.at (R.K.) \\ * Correspondence: jakob.siedersleben@uibk.ac.at
}

check for updates

Citation: Siedersleben, J.; Jocham, S.;

Aufleger, M.; Klar, R.

Morphodynamic Modelling with Uncertain Geometry Input. Water 2021, 13, 2248. https://doi.org/ $10.3390 / w 13162248$

Academic Editor: Bommanna Krishnappan

Received: 30 June 2021

Accepted: 14 August 2021

Published: 17 August 2021

Publisher's Note: MDPI stays neutral with regard to jurisdictional claims in published maps and institutional affiliations.

Copyright: (C) 2021 by the authors. Licensee MDPI, Basel, Switzerland. This article is an open access article distributed under the terms and conditions of the Creative Commons Attribution (CC BY) license (https:/ / creativecommons.org/licenses/by/ $4.0 /)$.

\begin{abstract}
For morphodynamic modelling, riverbed survey data are essential as the basis for the evaluation of temporal riverbed development, mesh creation, and model calibration. To study the effects of uncertain geometry input on these issues, datasets of different spatial resolutions were analysed. As a result, cross-profile data were derived from high-resolution survey data, which are available for a river reach in the Upper Danube in Bavaria for several periods. Finally, the prediction quality of simulations based on cross-profile and high-resolution spatial data was assessed. The analysis of both datasets shows continuous riverbed erosion but of different magnitudes. However, complex riverbed geometry due to, e.g., scours, is depicted poorly by cross-profile data. In more homogenously characterised reaches, cross-profile data significantly more closely represents the riverbed geometry than the high-resolution spatial data base. Local misinterpretation of riverbed geometry by cross-profile data leads to deviations of calibration parameters in the entire study area. Consequently, these deviations in calibration outcome effect the model predictions. In this case, cross-profile calibration generally induces higher transport capacities, leading to more erosion in the study area compared to the model based on high-resolution spatial calibration. The general shape of predicted riverbed geometries is found to be similar but with local deviations, which are not limited to areas with complex river geometry.
\end{abstract}

Keywords: morphodynamic modelling; sediment transport; cross-profile data; airborne laser bathymetry

\section{Introduction}

Two-dimensional morphodynamic numerical modelling is dependent on various input parameters that are subject to several sources of uncertainty. For example, bathymetric data is essential to correctly represent riverbed geometry and is used for mesh creation and calibration [1]. Consequently, numerical calculations of water surface elevation, water depth, depth-averaged velocities, and boundary shear stress strongly depend on the input data [2].

However, the acquisition of bathymetric data is expensive, and difficult to execute due to the dynamic nature of riverine environments (e.g., changing water levels, continuous changing bed morphology, or difficult approachability) [3]. This results in strong temporal and spatial limitations of geometric data, increasing the uncertainty of numerical models [4].

Two different types of datasets are commonly used: (i) Cross-profile data, which can be obtained with either traditional survey equipment in wadable water, or with hydroacoustic instruments (e.g., sonar, ADCP) mounted to a watercraft in deep water. (ii) Spatial data, which can be acquired with boat-mounted sonar or a LIDAR (Light Detection And Ranging) system. However, each survey technique has its own advantages and disadvantages. For instance, cross-profile survey data may not cover essential features of a riverbed such as scours, boulders, or other local structures, and the river channel between the cross-profiles must be interpolated [1]. Sonar data may be incomplete due to the inaccessibility of shallow 
waters [5]. Considering LIDAR data, gaps may occur due to significant water depths or high water turbidity [6]. Therefore, approaches to fill these data gaps are essential to avoid bias. Combined, these individual drawbacks lead to increased uncertainty of the obtained river bathymetry depending on survey techniques, data processing, and the riverine environment.

The effects of uncertainty influence calibration values, such as the critical Shields parameter used to determine the initiation of sediment motion [7], or the Strickler value, used to calibrate the roughness and thus the bottom shear stress [8,9]. Furthermore, errors due to geometry input uncertainties can propagate through the whole modelling process making morphodynamic observations prone to errors [4].

There is a wide range of publications covering the influence of cross-profile interpolation on river hydraulics $[1,10,11]$ and in [12] uncertainty analysis is applied concerning morphodynamic input parameters such as $\theta_{\text {crit }}$. However, the effects of cross-profile to cross-profile interpolations on morphodynamic modelling have been scarcely examined. The use of spatial geometric data in morphodynamic modelling is increasingly more common $[8,13,14]$, and both cross-profile and spatial data can be used in tandem [15]. However, there is still a lack of research regarding how predictions of morphodynamic models calibrated against cross-profile data may have different output predictions in terms of mean elevations and mean changes in volume, compared to morphodynamic models calibrated against spatial data.

In practice, researchers and project engineers are often faced with a variety of datasets differing in spatial resolution, thus demanding an analysis of how spatial and interpolated cross-profile survey data may lead to different interpretations of river geometry, and thus influence the calibration and predictions of morphodynamic simulations.

\section{Materials and Methods}

\subsection{Study Area}

The study area covers the Danube River from river kilometres 2508.0 to 2511.8 , in the Donauwörth region of Bavaria, Germany. The Danube has been subject to multiple anthropogenic impacts resulting from "Danube Corrections". These include river course straightening and narrowing combined with bank stabilisation, which has increased flow velocity and shear stress. River modifications, combined with several hydropower plants that act as transverse structures controlling the discharge and hindering longitudinal sediment transport to the downstream area, result in increased riverbed erosion [16]. The river has a constant width of approximately $70 \mathrm{~m}$ and an averaged riverbed inclination of $0.2-0.3 \%$. For an MQ discharge, the average water depth is $2.24 \mathrm{~m}$ and the maximum depth is at $6.61 \mathrm{~m}$. Several samples of bed material show a $d_{m}=20-30 \mathrm{~mm}$.

In the project area, tributaries to the Danube are the Schmutter, Zusam, and Wörnitz. Characteristic discharge values are listed in Table 1, where NNQ is the lowest ever measured discharge, MQ is the mean discharge over the recorded time, and HHQ is the highest measured discharge ever measured. Figure 1 shows an overview of the project area.

Table 1. Characteristic discharges of the Danube and its tributaries.

\begin{tabular}{|c|c|c|c|c|}
\hline River (Gauge) & $\begin{array}{l}\text { Observation } \\
\text { Period }\end{array}$ & $\mathrm{NNQ}\left[\mathrm{m}^{3} / \mathrm{s}\right]$ & $\mathrm{MQ}\left[\mathrm{m}^{3} / \mathrm{s}\right]$ & $\mathrm{HHQ}\left[\mathrm{m}^{3} / \mathrm{s}\right]$ \\
\hline Danube (Donauwörth) & 1980-2012 & 42.6 & 191.0 & 1340.0 \\
\hline Schmutter (Druisheim) & 1965-2016 & 0.7 & 3.7 & 81.4 \\
\hline Zusam (Pfaffenhofen) & $1931-2012$ & 1.4 & 4.1 & 64.5 \\
\hline Woernitz (Harburg) & 1970-2016 & 0.5 & 11.5 & 444.0 \\
\hline
\end{tabular}




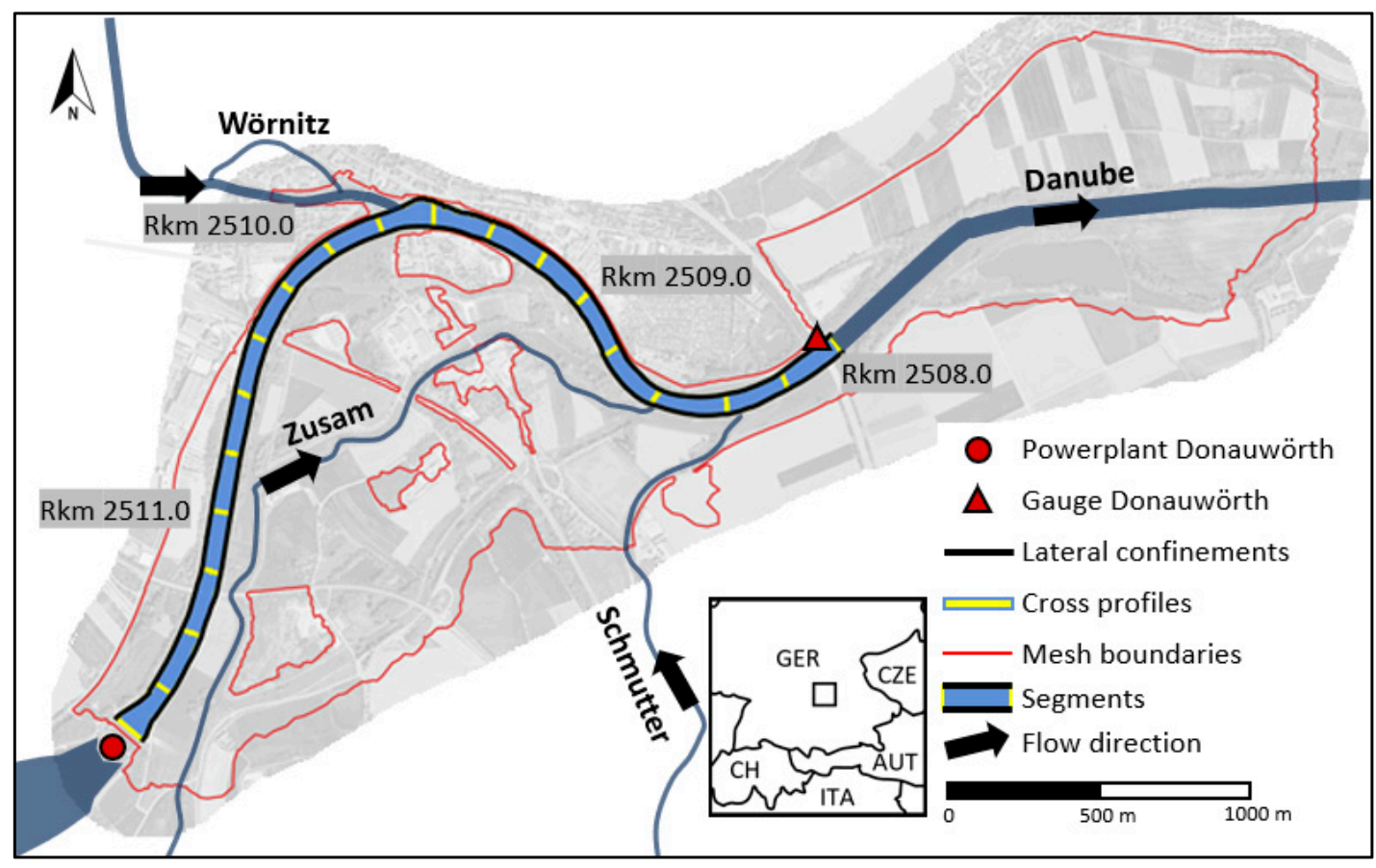

Figure 1. Overview of the study area in Donauwörth.

\subsection{Survey Data}

\subsubsection{Cross-Profile Survey Data}

From 1985 to 2020, overall, thirteen terrestrial cross-profile data surveys were carried out. The cross-profiles contain the riverbed, the banks, and a small part of the surrounding topography. Earlier surveys yielded fewer points whereas more recent surveys provided more detail; depending on the year, 30-160 points/profile are available. The point-to-point distance varies from 0.5 to $3 \mathrm{~m}$, and the cross-profile spacing is at $200 \mathrm{~m}$.

\subsubsection{Sonar Survey Data}

In 2013, 2018, and 2019, spatial data was collected with a boat-mounted multi-beam echo sounder. Rasterised point clouds with a spatial resolution of $1 \mathrm{~m}$ were generated from the survey data. For 2013, two survey datasets are available, one before the HQ10 June flood event (in the following denoted by 2013 or 2013-1) and one after the HQ10 June flood event (in the following denoted by 2013-2). However, data gaps are present in areas that were inaccessible by boat due to shallow water, rapids, and riverbanks.

\subsubsection{Airborne Lidar Bathymetry (ALB) Data}

In 2020 an Airborne Lidar Bathymetry survey was conducted resulting in a rasterised point cloud of the entire study area with a spatial resolution of $0.25 \mathrm{~m}$ [17]. The point cloud contains the entire riverbed, the banks, and the surrounding topography. Small data gaps occur in areas of deep water.

\subsection{Survey Data Processing}

The data was pre-and post-processed with the software "Surface-Water Modelling System" (SMS) using an analysis mesh, which is restricted to the riverbed and extracted from the calculation mesh used for numerical modelling.

The goal was to understand the development of the riverbed elevation over time, which required the evaluation of changes in mean elevation and volume for defined segments. Segments were defined by the river kilometres analogous to the distribution of cross-profiles shown in Figure 1. Lateral dimensions of the segments were determined by tracing the riverbanks using orthophotos of the study area. Figure 1 shows the geometrical 
elements used for survey data processing. Subsequently, the riverbed elevation and change in volume for each segment were able to be calculated.

\subsubsection{Spatial Data}

To prepare point clouds for calculating mean riverbed elevation, data gaps must be filled. Three different approaches were conducted to fill occurring data gaps, as shown in Figure 2:

- Interpolation of adjacent points.

- Filling data gaps with points derived from another spatial dataset, which was surveyed at a similar time.

- Data for non-erodible areas were generally derived from the 2020 ALB dataset due to its completeness.

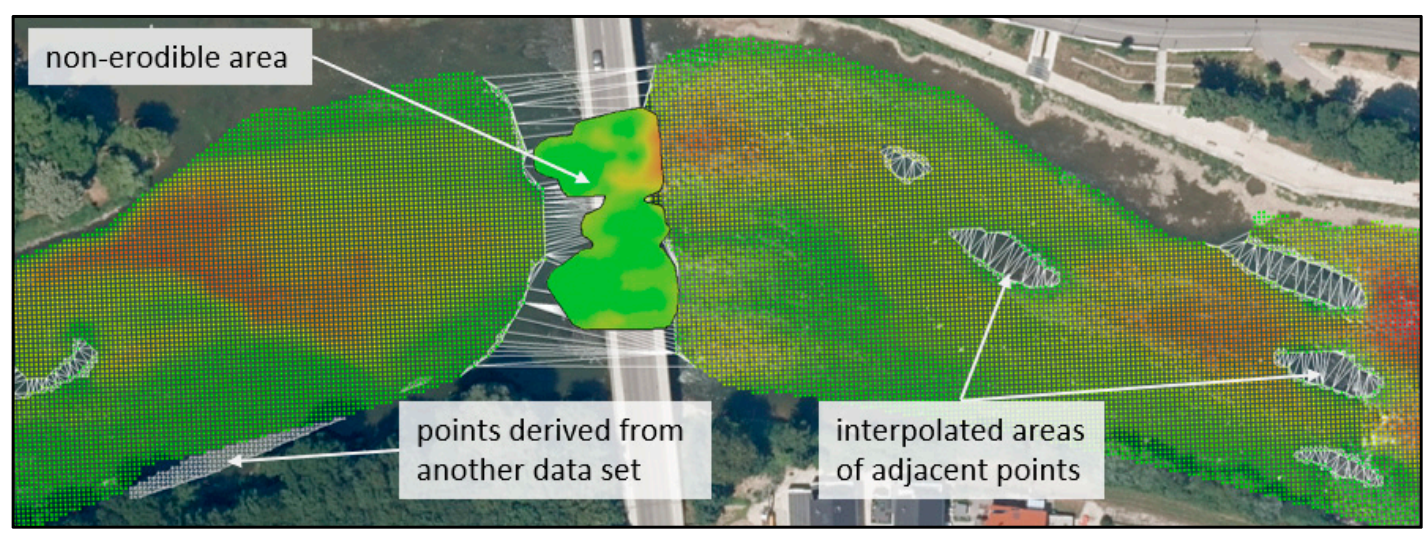

Figure 2. Filling methodology example of a DTM at Augsburger bridge for the 2013-2 dataset with a spatial resolution of $1 \mathrm{~m}$.

Finally, high-resolution rasterised terrain models representing different time periods were obtained. These terrain models were subsequently interpolated to the analysis mesh, as illustrated in Figure 3a. In the following, spatial data is denoted by "SPA".

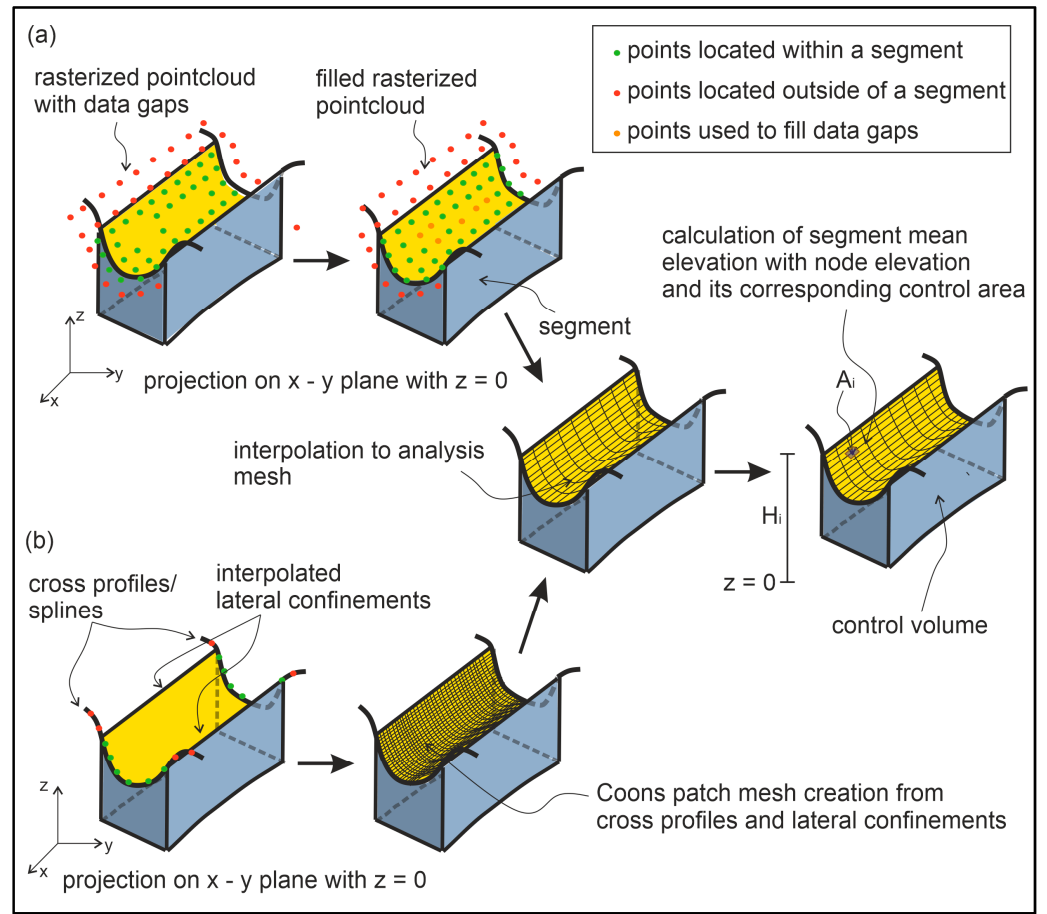

Figure 3. Procedure of mean elevation calculation for SPA data (a) and DCP data (b). 


\subsubsection{Derived Cross-Profile Data}

Data from the original cross-profile surveys (see Section 2.2.1 Cross-Profile Survey Data) were not used, because the measurement times differed significantly from those of the spatial-data surveys (Section 2.2.2 Sonar Survey Data and Section 2.2.3 Airborne Lidar Bathymetry (ALB) Data), making a qualified data comparison impossible. To still enable analysis of the difference between cross-profile and spatial datasets, cross-profiles were derived from the processed spatial data 2013-1 (sonar), 2013-2 (sonar), 2018 (sonar), and 2020 (ALB).

The position of the cross-profiles corresponds to the river kilometres with a profile-toprofile distance of $200 \mathrm{~m}$. The profile spacing was chosen as an analogue to the original cross-profile surveys and helps to put the existing cross-profile measurements in context. The following procedure, as illustrated in Figure $3 \mathrm{~b}$, was applied to prepare the derived cross-profile data to obtain the average elevation of the examined riverbed segments:

- Deduction of splines from cross-profile points.

- Intersection of splines with the lateral confinements connecting two neighbouring cross-profiles, defining a segment.

- Elevation interpolation onto lateral confinements connecting two neighbouring crossprofiles.

- Creation of a mesh derived from the cross-profiles and the lateral confinements according to the Adaptive Rectangular Coons Patch method [18].

- The Coons mesh is interpolated to the analysis mesh to calculate the mean riverbed elevation.

In the following, derived cross-profile data is denoted by " $\mathrm{DCP}$ ".

\subsection{Mean Elevation Calculation}

The mean elevation of a segment $\mathrm{H}_{\text {mean }}$ was calculated by the sum of the elevation $\mathrm{H}_{\mathrm{i}}$ of the single nodes of the analysis mesh weighted by its corresponding control area $\mathrm{A}_{\mathrm{i}}$ (Equation (1)). The analysis mesh was acquired according to the procedure in Figure 3.

$$
\mathrm{H}_{\text {mean }}=\frac{1}{\mathrm{~A}} \sum_{\mathrm{k}=0}^{\mathrm{n}} \mathrm{A}_{\mathrm{i}} * \mathrm{H}_{\mathrm{i}}
$$

The change in volume was then calculated according to the following equation:

$$
\Delta \mathrm{V}=\mathrm{A}_{\text {segment }} *\left(\mathrm{H}_{\mathrm{i}}-\mathrm{H}_{\mathrm{j}}\right)
$$

\subsection{Development of Riverbed Elevation}

Figure 4 shows a longitudinal section for the calculated mean elevations of the years 2013 and 2020 based on SPA and DCP data. SPA data suggests that continuous riverbed erosion occurred during the observation period. The mean erosion magnitude from 2013 to 2020 was around $21 \mathrm{~cm}$. The low point at river kilometre 2510.3 was caused by a local scour which was naturally filled until 2018.

DCP data suggests similar riverbed developments as SPA data. However, segments affected by prominent riverbed features, such as local scour at 2511.3/2511.1, 2510.3, 2510.1 , the anthropogenically influenced zones at 2509.7/2509.5, and segments affected by a confluence at river kilometres 2508.7 and 2508.5 , are depicted poorly. To clarify the differences between SPA and DCP data, the local scour at river kilometre 2510.3 is examined in detail in Section 5.1 Local Scour at River Kilometre 2510.3. 


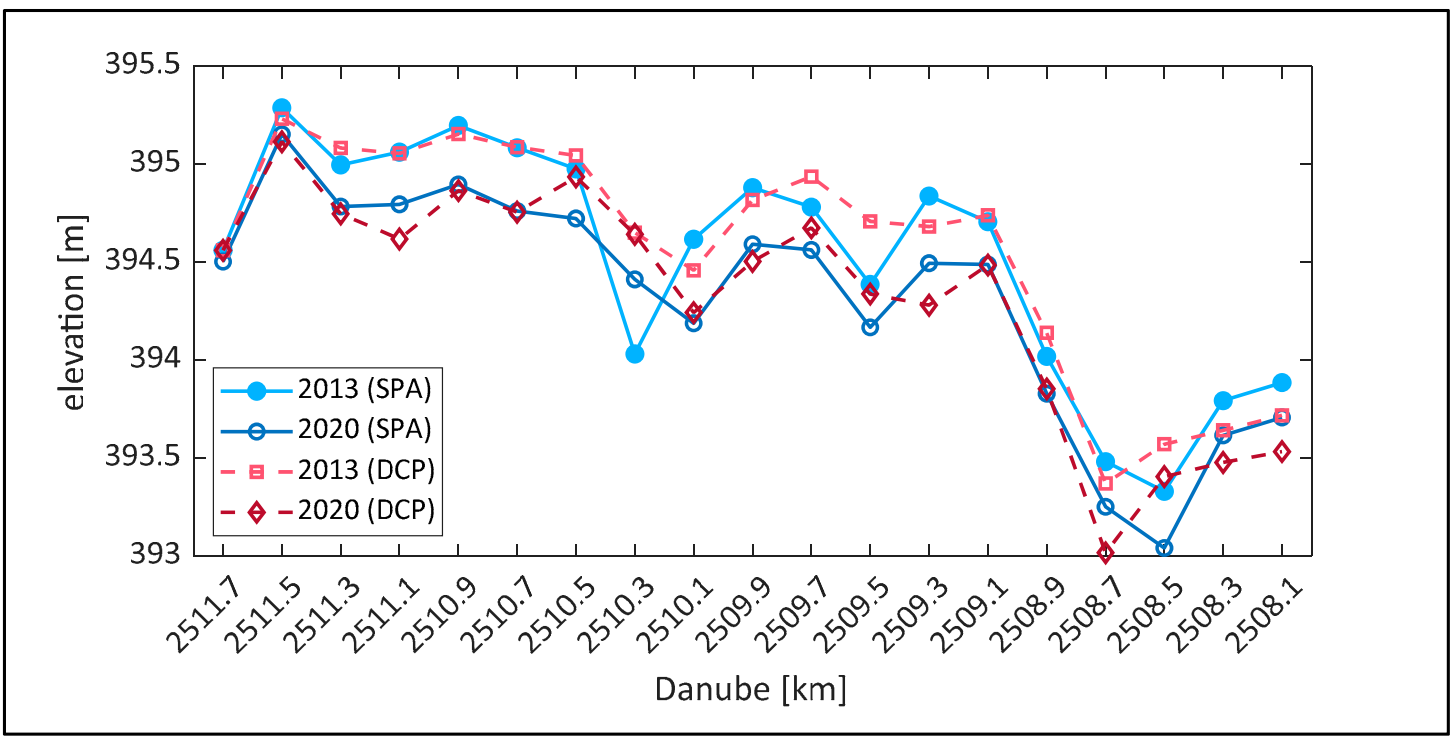

Figure 4. Development of the mean riverbed elevation for SPA data and DCP data from 2013 to 2020.

Figure 5a compares the change in elevation from 2013 to 2020 for SPA and DCP datasets. They correspond to the gradients of the cumulative change in volume shown in Figure 5b. For example, due to a positive value of SPA data at segment 2510.3 in Figure 5a, a positive gradient at segment 2510.3 in Figure $5 \mathrm{~b}$ can be observed.
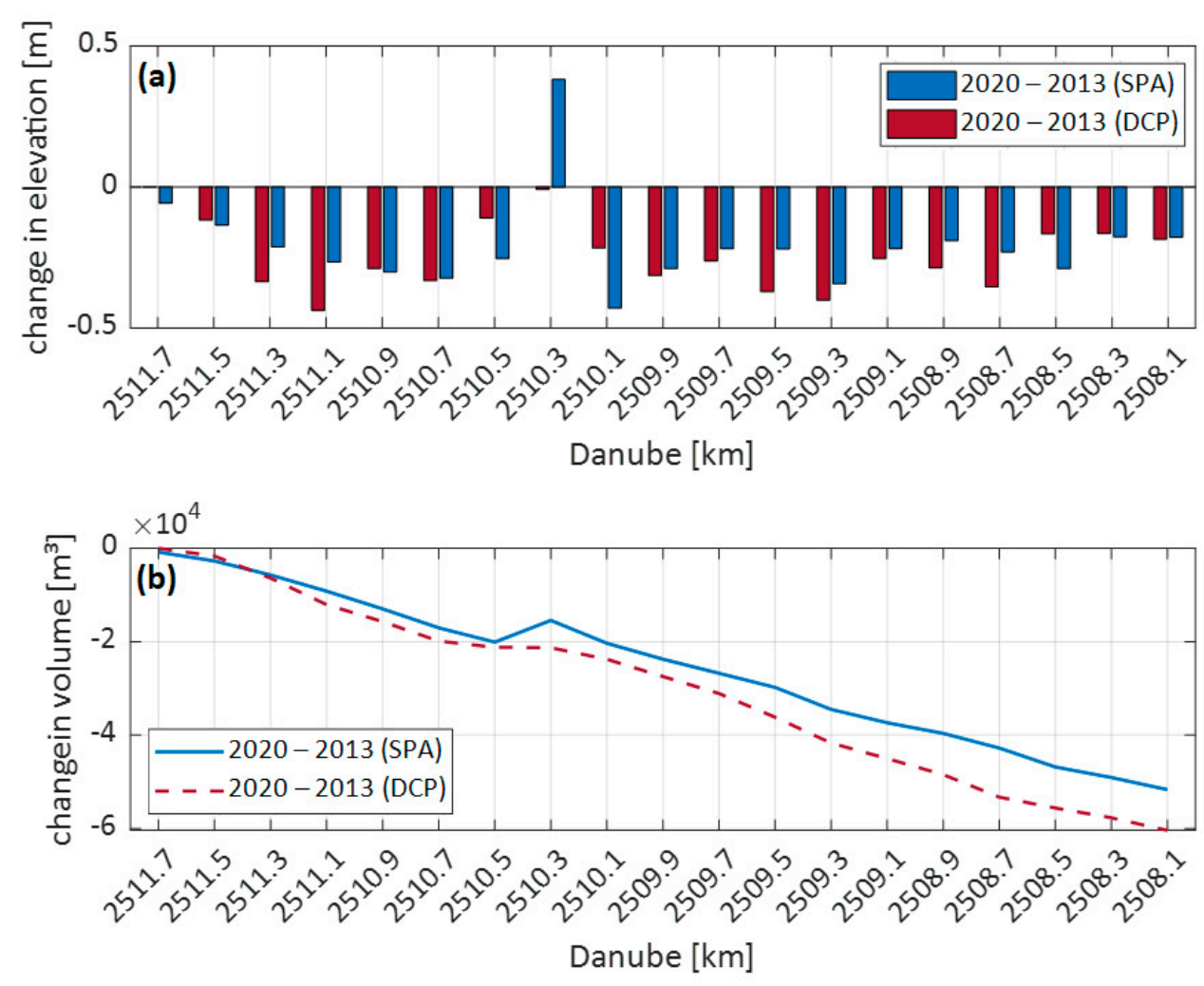

Figure 5. Comparison of change in elevation of SPA and DCP data for 2020-2013 (a) and comparison of the accumulated change in volume for 2020-2013 (b).

According to the SPA dataset, the entire river reach is subject to a decrease in riverbed elevation, except the segment at river kilometre 2510.3, where the already described natural 
filling of a scour occurs. During the observation time period, $51,000 \mathrm{~m}^{3}$ of riverbed material was discharged according to SPA data and 60,000 $\mathrm{m}^{3}$ according to DCP data. This results in an overall inaccurate depiction of the riverbed geometry, leading to a $16 \%$ overestimation of the discharged material in the entire study area when using DCP data compared to the SPA data.

\section{Numerical Model}

\subsection{Model Description}

Hydro_FT-2D is applied for sediment transport modelling, and is software that is fully coupled with the hydraulic solver Hydro_AS-2D $[19,20]$. The software computes the flow variables by solving the shallow water equations with a spatial discretisation according to the finite volume method. It uses a linear computation mesh consisting of triangular and rectangular elements, approximating the bathymetry and topography for certain time steps. Sediment transport is modelled according to Meyer-Peter and Müller [21] and an extension according to Hunziker [22] for multi-fractional transport. This multi-grain approach allows up to 12 grain size classes. The riverbed stratification is represented by a three-layer modelling approach, allowing for erosional, depositional, and armouring simulations.

Additionally, the model considers influences of the river bend and the slope in the longitudinal and transversal directions. The riverbed evolution is determined by solving the Exner equation. The internal time step is generally determined by the software with a CFL criteria of 0.8 .

For mesh creation, the definition of boundary conditions, and the processing/visualisation of computational results, the pre- and post-processor SMS surface water modelling software is used.

\subsection{Model Setup}

Two morphodynamic models were established, one based on SPA data and one based on DCP data. Figure 1 shows the computational mesh boundaries. The mesh resolution was defined carefully to maintain quality and acceptable computation speeds according to experience from previous works $[2,9,13]$. The river channel is represented by rectangular elements with dimensions of about $6 \times 3 \mathrm{~m}$. The surrounding topography is generally represented by triangular elements differing in size, dependent on its complexity. In total, 122,626 elements and 75,942 nodes represented the study area. The entire riverbed, with the exceptions mentioned in Section 2.3.1 Spatial Data, is defined as erodible.

\subsection{Calibration}

\subsubsection{General Concept}

The calibration process is divided into global and local calibration. Global calibration is successful when the results represent the shape, elevation, and evolutionary pattern of the riverbed as it was documented by survey data for a given period. This is achieved by adjusting global parameters such as $\theta_{\text {crit }}$, and defining initial sediment transport and $\mathrm{k}_{\mathrm{r}}$, which is a factor used for scaling the magnitude of sediment transport. For both setups (SPA and DCP), it was assumed that an identical global calibration setup is valid.

Local calibration was conducted by adjusting the segmental Strickler values while reducing deviations of the mean riverbed elevation and the cumulative change of volume to a minimum in respect to the survey data.

The calibration parameter used for local adaptations was the roughness value $\mathrm{k}_{\mathrm{St}}$, which was defined for each segment. Exceptions were areas with heterogenic bathymetry where it could be assumed that local flow patterns strongly affect sediment transport.

\subsubsection{Time Period}

The morphodynamic model was calibrated for the time period from 2013 to 2020. To minimise the simulation time, the Danube hydrograph was limited to discharges over 
$500 \mathrm{~m}^{3} / \mathrm{s}$, when major sediment transport is assumed to occur. The resulting time period was equivalent to 54 days.

\subsection{Validation}

Model validation was not explicitly conducted, but during the calibration time period, additional survey datasets from 2013 and 2018 were available and used to globally validate the morphodynamic model by assessing intermediate time steps.

\section{Results}

\subsection{Calibration}

\subsubsection{Global Calibration}

The model setup used six particle size classes to represent sediment ranging from 2 to $152.5 \mathrm{~mm}$. The internal acceleration factor for sediment transport was set to 4 . During the global calibration process, values of 0.036 for the critical Shields parameter $\theta_{\text {crit, }}$ and 1 for the sediment transport scaling factor $\mathrm{k}_{\mathrm{r}}$, were determined. The Strickler value was set at $37 \mathrm{~m}^{1 / 3} / \mathrm{s}$ for the entire river reach.

\subsubsection{Local Calibration}

Figure 6a shows a longitudinal section of the initially used and calibrated Strickler values for the entire study area, for both SPA data and DCP data based models. Due to the complex riverbed geometry with bridge foundations at river kilometres 2509.5 and 2509.7, Strickler values were set explicitly low to $27.5 \mathrm{~m}^{1 / 3} / \mathrm{s}$, leading to a mean Strickler value for the Danube of $35.1 \mathrm{~m}^{1 / 3} / \mathrm{s}$ according of the SPA data mesh. The mean Strickler value for the Danube according to the DCP data mesh is $34.1 \mathrm{~m}^{1 / 3} / \mathrm{s}$. The error of the simulated segmental riverbed elevation in respect to the survey data is less than $5 \mathrm{~cm}$ for both simulations.
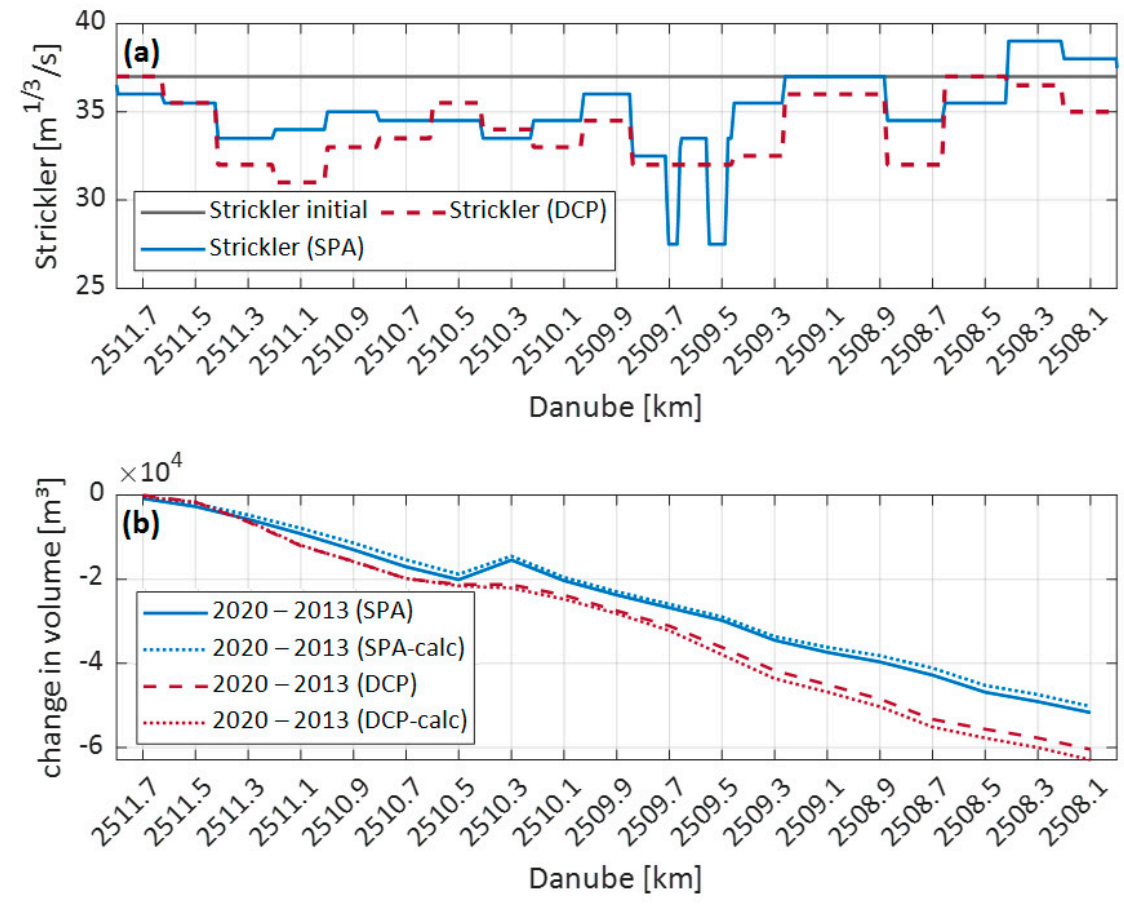

Figure 6. Initial Strickler values and calibrated Strickler values for SPA and DCP data (a) and a comparison of calculated and simulated cumulative change in volume (b).

Figure $6 \mathrm{~b}$ compares the cumulative change in volume as simulated by SPA and DCP data in comparison to the corresponding SPA and DCP survey data. In respect to the survey 
data, the simulated change in volume differs by less than $2.9 \%$ for the SPA simulation and less than $4.2 \%$ for the DCP simulation.

\subsection{Morphodynamic Predictions}

Aiming to evaluate the two different datasets, two morphodynamic simulations were conducted, covering a time period equivalent to the calibration simulations. The SPA prediction model was set up with the initial riverbed geometry defined according to the survey dataset 2020 (SPA) and the segmental Strickler values corresponding to the SPA calibration. The DCP prediction model was set up with the initial riverbed geometry defined according to the survey dataset 2020 (DCP) and the segmental Strickler values corresponding to the DCP calibration.

The longitudinal section of the predicted mean riverbed elevations of the two models are compared in Figure 7a. Although the shape of the two curves looks similar, local deviations occur at river kilometres 2511.1, 2510.9, 2509.3, 2508.7, and 2508.5, leading to local under- or overestimations of the mean riverbed elevation. Notable are the deviations that do not necessarily occur at segments with complex river geometry. Additionally, the cumulative change in volume of the SPA data model is exceeded by $22 \%$ of the simulation based on the DCP calibration, resulting in a lower mean riverbed.
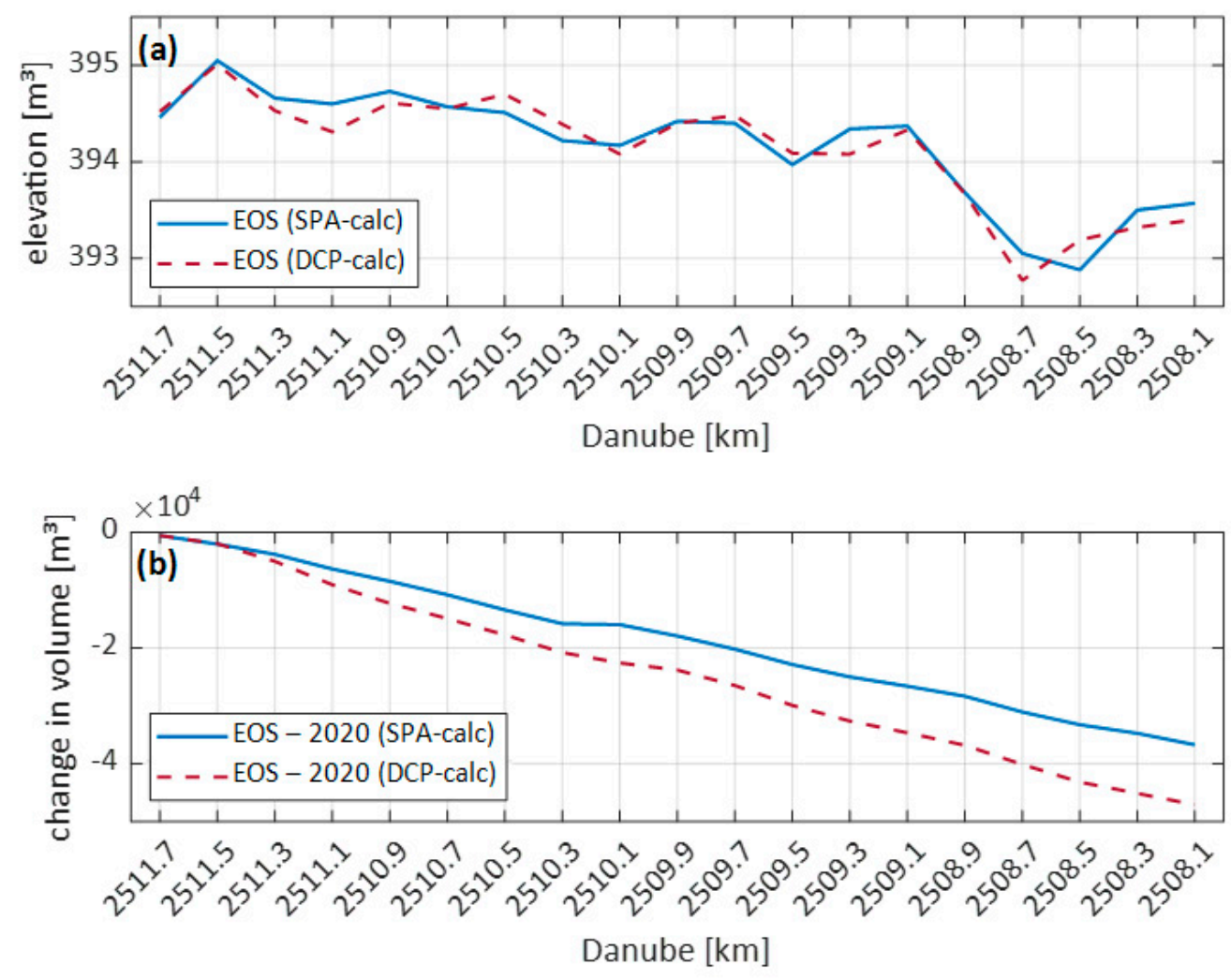

Figure 7. Elevation at the end of simulation (EOS) as simulated by spatial (SPA-calc) and derived cross-profile (DCP-calc) data (a) and the cumulative change in volume for SPA and DCP simulations (b).

\section{Discussion}

\subsection{Local Scour at River Kilometre 2510.3}

Figure 8 shows the longitudinal profiles between river kilometres 2510.0 and 2510.6 for SPA (a) and DCP data (b) from 2013 and 2020. Additionally, corresponding spatial 
illustrations of the differences in riverbed elevation from 2013 to 2020 are given for SPA (c) and DCP data $(\mathrm{d})$.
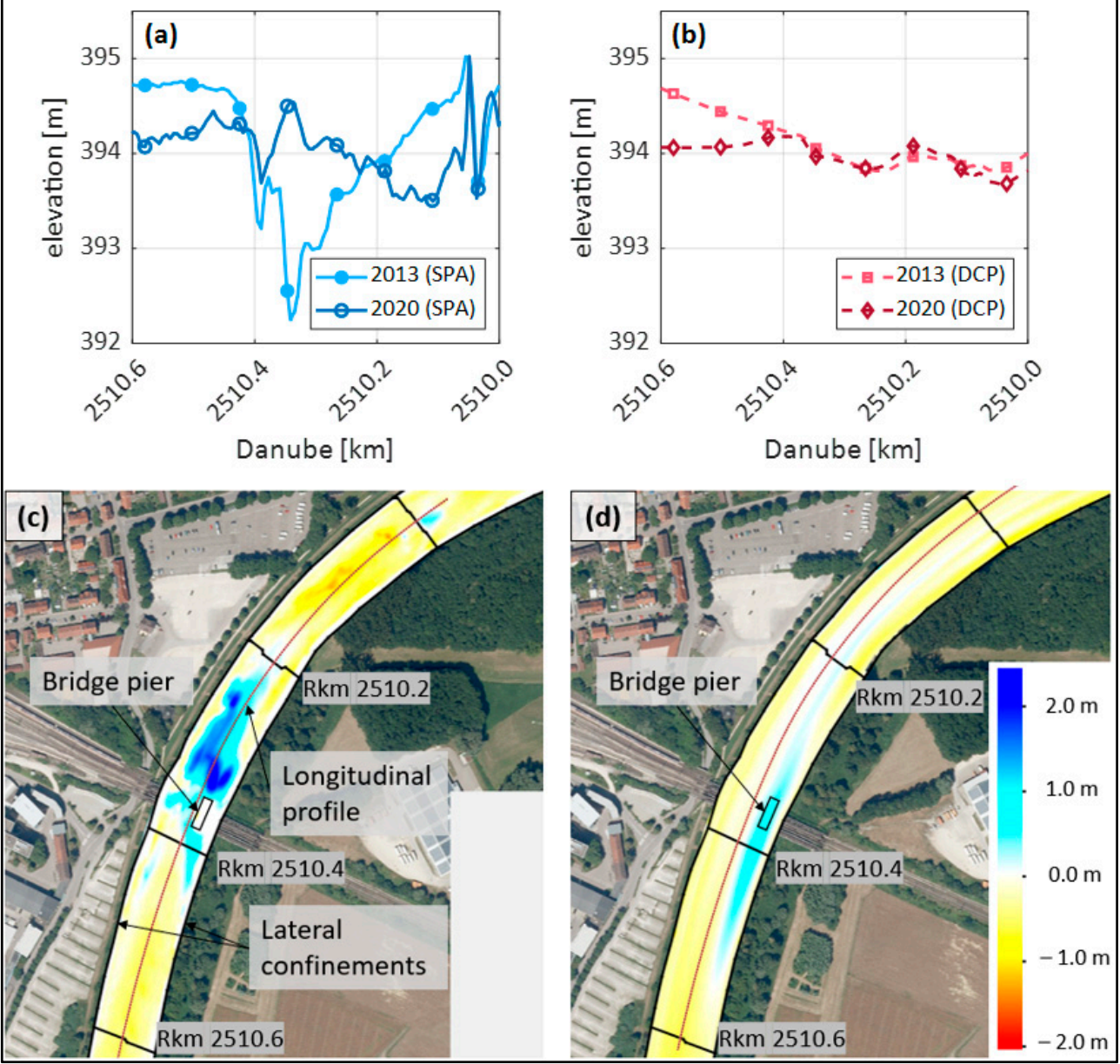

Figure 8. Longitudinal profiles for 2013 and 2020 for SPA (a) and DCP data (b), and the corresponding elevation difference from 2013 to 2020 for SPA (c) and DCP data (d).

Between river kilometres 2510.4 and 2510.2, a scour downstream of the railroad bridge is covered by the 2013 SPA data due to the cross-section narrowing imposed by the bridge pier. According to SPA data, from 2013 to 2020 the scour was naturally filled, leading to an increase in the riverbed elevation of up to $2 \mathrm{~m}$. The riverbed elevation of the adjacent segments decreased up to $1 \mathrm{~m}$. The zones closest to the lateral confinements/riverbanks do not show any elevation changes. This is due to point cloud processing, as explained in Section 2.3.2 Spatial Data. Sonar point clouds generally do not contain the riverbanks. Thus, major parts of the riverbanks were derived from the 2020 ALB data and are identical throughout the spatial datasets.

DCP data suggest a different situation: Due to the occurrence of the local scour between two cross-profiles, the bathymetry cannot be described properly. Although there is sediment deposition immediately downstream of the bridge foundation, a comparison of both illustrations shows that the actual morphology in this area is poorly described. Additionally, a longitudinal profile view does not show significant changes in this area and the bridge pier is not covered by the dataset. 


\subsection{Represenentation of Riverbed Elevation}

As suggested by Figure 4, DCP data generally displays riverbed features but fails to provide a detailed view of the complex riverbed geometry, resulting in a smoothed depiction of the riverbed geometry.

In this study, DCP data suggests an increase in riverbed erosion during the calibration time in comparison to SPA data. This behaviour requires representation in the numerical simulation with an adequate parameter setup, inducing increased bed load transport. Segmental Strickler values were used to locally adapt transport capacities to the measured data. Subsequently, Strickler values of DCP calibration were found to be rougher than those of SPA calibration.

It was observed that the determined Strickler values differed over the entire study area and were not limited to local areas, as might be assumed. Consequently, the segmentally differing levels of transport capacity propagate through the predictions of the morphodynamic model, resulting in an overall increase in riverbed erosion as predicted by DCP data compared to SPA data. This leads to deviations in mean riverbed elevation, which do not necessarily manifest at segments with complex river geometry but occur over the entire river reach. This indicates that the misinterpretation of local features affects the predictions of morphodynamic models in the entire study area and is not limited to local areas.

The deviations in this study are limited to $30 \mathrm{~cm}$ for segmental mean riverbed elevation for a prediction time of 7 years. However, with increasing simulation time, errors may accumulate and result in increasing prediction uncertainty. These uncertainties can be reduced by the use of SPA data, which gives a wider and more detailed look at the development of riverbed geometry. However, the correct treatment and processing of data is essential and requires more knowledge; for example, the filling of data gaps due to riverbanks and scours.

However, in many projects the availability of SPA survey datasets with a high temporal resolution is not guaranteed, requiring combined usage of SPA and cross-profile $(\mathrm{CP})$ datasets, or the sole use of $\mathrm{CP}$ datasets. Because $\mathrm{CP}$ data aims to depict a similar general riverbed development to that of SPA data, neglecting local differences, it can be used as supplementary information, thereby improving the geometric database of a project. For example, $\mathrm{CP}$ data acquired by ADCP allows depth measurement accuracies of $1 \%$, possibly providing more accurate information within the cross-profile [23]. This data may be used to validate other conducted surveys, such as sonar and ALB, and hence improve the calibration and prediction quality of morphodynamic models. Additionally, if deviations of mean elevation and change in volume are kept within a certain range and meet the requirements of a project, sole use of $\mathrm{CP}$ data does not necessarily lead to drawbacks and may simplify the processing of survey data.

The segmental calculation of mean elevation, as undertaken in this work, raises the question of whether this method provides adequate accuracy in comparison with highresolution spatial data. By utilising smaller segments, the complex riverbed geometry, as depicted in the high-resolution data, can be considered in the local calibration of Strickler values. Therefore, a better depiction of riverbed roughness may yield improved morphodynamic prediction quality.

\section{Conclusions}

The availability of high-resolution bathymetry data is constantly increasing, raising questions of whether morphodynamic predictions can be improved and how they differ in comparison to predictions based on traditional cross-profile data. Therefore, this study aimed to evaluate the impact of spatial and cross-profile data on calibration and predictions of $2 \mathrm{~d}$ morphodynamic models.

For a river reach in the Bavarian Danube, several spatial high-resolution point clouds (SPA) are available, which were additionally used to derive cross-profile (DCP) data with a cross-profile spacing of $200 \mathrm{~m}$. 
Based on each dataset, riverbed development was evaluated, two morphodynamic models were calibrated, and their morphological predictions were compared. SPA data represent the entire river reach in detail, and provide highly comprehensive coverage prominent features. On the contrary, the representation of riverbed geometry by DCP data is smoothed in the longitudinal direction due to the interpolation of the riverbed geometry between two cross-profiles. However, the accuracy of a cross-profile survey may surpass the accuracy of common sonar and ALB surveys, resulting in highly accurate depictions of local profiles. These profiles can be used to validate the accuracies of other surveys, such as ALB and sonar. However, prominent local features, such as scours, foundations, or confluences, may be missed entirely or covered only partially. This leads to a factor of randomness when using cross-profiles for morphodynamic modelling. However, zones having a homogeneous riverbed geometry, and lacking a complex riverbed geometry, are represented well and the use of cross-profile data shows few or no drawbacks compared to the use of SPA data.

Calibration was achieved by adjusting the local Strickler values, defined for $200 \mathrm{~m}$ segments of the Danube River, against survey data from 2013 to 2020. In comparison to SPA data, DCP data overestimated the erosion of the entire river reach, resulting in a rougher mean Strickler value for the DCP calibration.

The DCP calibration setup induced more sediment transport, leading to a $22 \%$ increase in erosion, but was still able to represent the general shape of the riverbed geometry as predicted by SPA simulation. However, the misinterpretation of certain areas influenced the Strickler values over the entire study area, and led to local deviations, which were not limited to areas with prominent features but occurred over the entire study area.

Author Contributions: Conceptualization: J.S., S.J., R.K.; methodology, J.S., S.J., R.K.; software, J.S., S.J., R.K.; validation, S.J.; formal analysis, J.S.; investigation, J.S., S.J.; resources, J.S., S.J., R.K.; data curation, J.S.; writing-original draft preparation, J.S.; writing—review and editing, J.S., S.J., R.K.; visualization, J.S.; supervision, M.A.; project administration, R.K.; funding acquisition, R.K., M.A. All authors have read and agreed to the published version of the manuscript.

Funding: This research received no external funding.

Data Availability Statement: The authors confirm that the data supporting the findings of this study are available within the article.

Acknowledgments: Data was made available in the framework of two projects: the EU-LifeProject "City River" and a third party funded project evaluating the riverbed stability of the river Danube in Donauwörth (Germany).

Conflicts of Interest: The authors declare no conflict of interest.

\section{References}

1. Conner, J.T.; Tonina, D. Effect of cross-section interpolated bathymetry on 2D hydrodynamic model results in a large river. Earth Surf. Process. Landf. 2014, 39, 463-475. [CrossRef]

2. Jocham, S.; Wörndl, M.; Aufleger, M. Effects of mesh and survey resolution on 2D numeric hydrodynamic modelling in a mountain river. In Proceedings of the 36th IAHR World Congress "Deltas of the Future and what happens upstream", The Hague, The Netherlands, 28 June-3 July 2015.

3. Jocham, S. Untersuchungen zum Einsatz Hochauflösender Bathymetrischer LIDAR Daten in der 2d-Abflusssimulation und Habitatmodellierung. Ph.D. Thesis, Leopold-Franzens Universität Innsbruck, 2019. Available online: https://diglib.uibk.ac.at/ ulbtirolhs/content/titleinfo/ 4365520 (accessed on 13 August 2021).

4. Legleiter, C.J.; Kyriakidis, P.C.; McDonald, R.R.; Nelson, J.M. Effects of uncertain topographic input data on two-dimensional flow modeling in a gravel-bed river. Water Resour. Res. 2011, 47, 1-24. [CrossRef]

5. Horritt, M.S.; Bates, P.D.; Mattinson, M.J. Effects of mesh resolution and topographic representation in 2D finite volume models of shallow water fluvial flow. J. Hydrol. 2006, 329, 306-314. [CrossRef]

6. Dobler, W.; Steinbacher, F.; Baran, R.; Ritter, M.; Aufleger, M. High Resolution Bathymetric Lidar Data to Hydraulic-Modelling A Mountain Stream by Bathymetric Lidar Data. In Proceedings of the 11th International Conference on Hydroinformatics, New York, NY, USA, 17-21 August 2014.

7. Shields, A. Anwendung der Aehnlichkeitsmechanik und der Turbulenzforschung auf die Geschiebebewegung; Preussichen Versuchsanstalt für Wasserbau: Berlin, Germany, 1936. 
8. Klar, R. Langzeitsimulation des Geschiebetransports in alpinen Tälern: Weiterentwicklung von Methoden zur Modellierung der langfristigen Sohllagenentwicklung und zur Ermittlung von Hochwassergefahren in inneralpinen Tälern. Ph.D. Thesis, Forum Umwelttech, Wasserbau, 2016. Available online: https://diglib.uibk.ac.at/ulbtiroloa/content/titleinfo/2556531 (accessed on 13 August 2021).

9. Klar, R.; Baumgartner, K.; Jocham, S. Licca Liber-Weiterführende Untersuchungen. Anlage 5.2 GeschiebetransportmodellierungModellaufbau und Anpassung. 2017. Available online: https://www.wwa-don.bayern.de/fluesse_seen/massnahmen/ liccaliber/konzept/abschnitt_eins_und_zwei/doc/anlage_fuenfvier_gewaessermorphologische_langzeitprognose.pdf (accessed on 13 August 2021).

10. Caviedes-Voullième, D.; Morales-Hernández, M.; López-Marijuan, I.; Garcìa-Navarro, P. Reconstruction of 2D river bed by appropriate interpolation of $1 \mathrm{D}$ cross-sectional information for flood simulation. Environ. Model. Softw. 2014, 61, 206-228. [CrossRef]

11. Merwade, V.; Cook, A.; Coonrod, J. GIS techniques for creating river terrain models for hydrodynamic modeling and flood inundation mapping. Environ. Model. Softw. 2008, 23, 1300-1311. [CrossRef]

12. Beckers, F.; Noack, M.; Wieprecht, S. Uncertainty analysis of a 2D sediment transport model: An example of the Lower River Salzach. Phys. Ecol. Asp. Mob. Sediments 2017, 18, 3133-3144. [CrossRef]

13. Baumgartner, K. Analyse und Evaluierung der Praktischen Anwendung von Topo-Bathymetrischen LiDAR Daten in Alpinen Gewässern; Leopold-Franzens-Universität Innsbruck: Innsbruck, Austria, 2020.

14. McKean, J.; Tonina, D. Bed stability in unconfined gravel bed mountain streams: With implications for salmon spawning viability in future climates. J. Geophys. Res. Earth Surf. 2013, 118, 1227-1240. [CrossRef]

15. Matias, M.P.; Falcão, A.P.; Gonçalves, A.B.; Alvares, T.; Pestana, R.; Zeller, E.V.; Rodrigues, V.; Heleno, S. A methodology to generate a digital elevation model by combining topographic and bathymetric data in fluvial environments. In Proceedings of the ESA Living Planet Symposium, Edinburgh, UK, 9-13 September 2013.

16. Schmedtje, U. The Danube River Basin District; International Commission for the Protection of the Danube River: Vienna, Austria, 2005.

17. Steinbacher, F.; Pfennigbauer, M.; Aufleger, M. Airborne hydromapping area-wide surveying of shallowwater areas. In River Flow; Karlsruhe Bundesanstalt für Wasserbau: Karlsruhe, Germany, 2010; pp. 1709-1714.

18. Gonzales, D.S. An Automatic Finite Element Mesh Generation Method: The Adaptive Rectangular Coons Patch. Ph.D. Thesis, Brigham Young University, Provo, UT, USA, 2000.

19. Nujic, M.; Hunziker, R. Benutzerhandbuch Hydro_AS-2D—2d Strömungsmodell für die Wasserwirtschaftlichen Praxis; Hydrotec: Aachen, Germany, 2015.

20. Nujic, M.; Hunziker, R. Benutzerhandbuch Hydro_FT-2D—Erweiterung zu Hydro_AS-2D zur Simulation des Stofftransports; Hydrotec: Aachen, Germany, 2015.

21. Meyer-Peter, E.; Müller, R. Formulas for Bed-Load transport. In Proceedings of the International Association for Hydraulic Research, Third Annual Conference, Stockholm, Sweden, 7-9 June 1948; pp. 39-64.

22. Hunziker, R.; Vischer, D. Fraktionsweiser Geschiebetransport. VAW Mitteilung 1995, 138. Available online: https://ethz.ch/ content/dam/ethz/special-interest/baug/vaw/vaw-dam/documents/das-institut/mitteilungen/1990-1999/138.pdf (accessed on 13 August 2021).

23. Kasvi, E.; Salmela, J.; Lotsari, E.; Kumpula, T.; Lane, S.N. Comparison of remote sensing based approaches for mapping bathymetry of shallow, clear water rivers. Geomorphology 2019, 333, 180-197. [CrossRef] 